\title{
RASGOS DIFERENCIALES DE LA MORTALIDAD EN LAS MONTAÑAS LEONESAS DURANTE EL SIGLO XVIII
}

Julio TASCON

\section{1.-Introducción}

Durante la Edad Moderna, habitaban las montañas leonesas -que nombraré indistintamente como Montaña de Riaño- unos doscientos cincuenta grupos humanos, integrados en treinta y una demarcaciones (concejos, jurisdicciones, encartaciones, ...véase pág. 168). Estos colectivos se mantenían gracias a los reducidos esquilmos que sus ganados y tierras les proporcionaban. Todos trabajaban la tierra y todos pastoreaban sus ganados. Los animales que componían sus rebaños no superaban el número de los que se podrían mantener en los establos del lugar, durante los meses más inhóspitos del invierno. A lo largo del Antiguo Régimen no poseyeron grandes rebaños ovejunos más que excepcionalmente. Se ocuparon, sin embargo, en la pastoría trashumante de ganados finos. De este modo contribuyeron a la permanencia del grupo entre montañas. Sin la posibilidad de ocuparse en aquel trabajo estacional, ciertamente, muchos lugares se habrían despoblado. De hecho, la emigración definitiva era una característica perenne del comportamiento demográfico montañés.

Otros trabajos estacionales de menor duración, como la arriería otonal, les ayudaban a subsistir. Los trabajos artesanales y de manufacturas fueron desempeñados por un conjunto tan reducido de operarios, que su importancia para nuestro análisis resulta marginal.

La estructura socioprofesional que presentaban los efectivos poblacionales de entonces, así como la desigualdad mínúscula que existía entre sus ingresos 
permite afimar que aquellos lábriegos formaban un conjunto muy homogéneo, desde el punto de vista económico. La caracterización económica se hará con datos del siglo XVIII, pues de los disponibles son los de mayor fiabilidad para elaborar la estructura socioprofesional y realizar el tratamiento estadístico de la desigualdad de rentas. Las informaciones del siglo ilustrado son las únicas que permiten mostrar el estancamiento económico que padecieron los montañeses durante el Antiguo Régimen (véase TASCON, 1993). Los más pudientes, entre los vecinos fueron mayorazgos, algún que otro clérigo y otros señores residentes en la ciudad de León. Pero, generalmente, el Comán era uno de los mayores hacendados, cuando no el mayor hacendado por excelencia.

Los montañeses tenían poca, o más bien nula, conciencia de pertenecer al agregado que estudiamos. La conciencia de interacción se daba con toda seguridad, aunque resultaría difícil establecerla en sus más precisos términos. Las comunicaciones transversales eran mucho peores que las verticales, sin que ello impidiese las relaciones comerciales, entre otras. El ámbito regional de la Momtaña de Riaño era plenamente rural, sin que se conozca ningún fenómeno de urbanización relevante durante el Antiguo Régimen.

La mencionada agrupación de labradores/pastores será tratada como un conjunto socioeconómicamente diferenciado de los labradores de las tierras llanas leonesas, o bien de los que vivían en la España interior. La caracterización económica de estos labriegos montañeses permitirá un tratamiento de conjunto para analizar lid estacionalidad de las defunciones. De esta forma quedarán validadas las extrapolaciones del movimiento estacional de los óbitos. La caracterización económica enmarcada dentro de los límites definidos por los derechos de propiedad, nos autoriza a contemplar a los montañeses como un grupo social homogéneo.

Los montañeses detentaban un poder adquisitivo muy parecido y se enfrentaban a unas condiciones climatológicas, en general - ambientales- adversas. Ninguna epidemia se mostró especialmente destructiva, mientras la mortalidad ordinaria seguía su curso. La inmensa mayoría de los montañeses terían sus organismos pertrechados con idénticas armas para combatir las enfermedades. El medio físico de su habitat, las reducidas posibilidades económicas y el estrecho mercado interior, así permiten suponerlo.

Pero en condiciones económicas semejantes se encontraban otras áreas rurales, como las de las llanuras leonesas o las del interior español. Mostrar el comportamiento de la mortalidad respecto al clima en las montañas y las pautas diferenciales del movimiento estacional de la mortalidad respecto a las otras áreas geográficas constítuye el objetivo del presente trabajo. 
El espacio físico de alta montaña que nos ocupa comprende la vertiente leonesa del macizo Cantábrico. Los límites de la región son los de los partidos judiciales de la Vecilla y Riaño. Se trata de una extensión de $2.404 \mathrm{~km}^{2}$ que comprendía 31 demarcaciones (concejos, encartaciones,...), con 250 entidades de población (pueblos y villas). Dentro de estos límites encontramos perfectamente enmarcadas las divisiones administrativas del Antiguo Régimen. Nos hallamos ante una franja de terreno a caballo entre el interior y la periferia, que presenta un relieve con fuertes pendientes y una elevada altitud (la altitud media de aquellas aldeas ronda los $1.061 \mathrm{mts}$. s.n.m.). La región está clasificada como representativa de los sistemas agropastoriles montañeses.

Las condiciones del medio físico limitaban extraordinariamente las posibilidades de la agricultura. Es decir, que para los lugareños acceder a las economías de escala, teóricamente disponibles, resultaba una práctica repleta de fiascos y desánimo. Estos fracasos unidos a una débil productividad agraria estaban ligados al estancamiento tecnológico, para conseguir, durante el siglo de las luces, detener el crecimiento económico de la región. La ausencia de crecimiento se comprueba con la desocupación que generaban las diferencias entre renta potencial y real, para ciertos empleos. De este modo lo he comprobado para el siglo XVIII, aunque el período podría alargarse, desde luego, hasta mediados del siglo XIX.

Antes de nada, veamos las restricciones de un terrazgo tan exiguo como era el de aquellas montañas. La distribución del terrazgo era como sigue:

- tierras marginales de aprovechamiento pascícola $63 \%$

- tierras cerealistas $24 \%$

- tierras cereal-lino en alternancia $2 \%$

- prados secano $4 \%$

- prados regadío $6 \%$

- huertos $1 \%$

Los montañeses debían encontrar un equilibrio para mantener las adecuadas proporciones entre tierras y pastos. Esto sucedía así, porque existía una competencia ecológica entre ellos y sus animales por el espacio agrícola útil. La competencia se dejaba sentir, sobre todo, con relación a los «ganados mayores».

El estancamiento de las técnicas empleadas se puede verificar siguiendo la evolución de los precios que alcanza el ganado dentro de la región. Las series reconstruidas expresan la presión de la demanda, a lo largo del siglo XVIII'.

\footnotetext{
' Véase TASCÓN (1991, 496-542).
} 
Claro que para la demanda local de «animalías", la principal motivación consistía en defender el equilibrio, tan necesario -imprescindible-, del sistema agro-pastoril que les permitía la subsistencia. Los pequeños cambios tecnológicos que surgieron aquí y allá, no transformaron los elementos fundamentales de la economía montañesa del siglo «iluminados. Me refiero, entre otros ejemplos, en la Montaña de Riaño, al descenso progresivo del cultivo del cereal de primavera -conicasa-, en el valle de Boñar; a los comienzos de un sistema de rotación trienal con alternancia de cultivos: cereal/legumbre/barbecho, en las montañas de Lillo; al aumento de la cabaña equina, o mejor dicho de *yeguas de vientre» en los pastos de Carande; aperturas hacia mercados exteriores, etc. ...todo ello hacia el final del siglo XVIII.

\section{3.-Clima}

Una idea de la influencia del medio físico sobre la salud la dan los diferentes climas según las estaciones y las variaciones estacionales de los óbitos [GUTIÉRREZ ROLDAN, 1989, 11].

Los datos de precipitaciones y temperaturas desde los años sesenta hasta hoy, serán, a falta de otras informaciones numéricas para siglos anteriores, los guarismos que ilustren la idea del clima qpie tuvieron los montañeses de la Edad moderna.

En lo fundamental, como ocurre en latitudes francesas, el clima del siglo XVIII y XIX eта similar al nuestro. El valor de las temperaturas sería el menos cambiante, puesto que la pluviosidad es un fenómeno más local.

Las fuentes documentales relatan, muy a menudo, la incomunicación de los pueblos causada por las muchas nieves. El aislamiento y la lalta de noticias eran frecuentes durante largas temporadas. Muchos años, por San Antonio 13 de junio) «todavía está frín y nevandos. La documentación de la época informa de unos cinco o seis meses de aislamiento invernal.

La región presenta un clima característico de «alta montaña», con relación a las tierras llanas y mesetarias do Lcón y Castilla. Los inviernos son largos. fríos y nivosos. De octubre a mayo ni dejan de ser cotidianas las heladas ní cejan las nevadas. En el centro del inviemo el frío es muy intenso, como lo ponen de manifiesto las temperaturas medias de enero en torno a los cero grados, bien negativas como en el caso del observatorio de Isoba. El verano erá corto, además de fresco. Incluso podía helar y nevar, aunque dichos meteoros tendrían carácter excepcional. Durante el estio había lluvias, aunque mermadas respecto a las del resto del año. También se producían brumas y nieblas du- 
rante el verano. Por todo lo cual la aridez estival casi no existía. El índice de Martome alcanza valores muy alejados del límite superior que Martonne situó para dicha aridez en $20^{2}$. Brevemente, es un clima frío y húmedo, en el que el corto verano más bien parece una primavera.

\section{Indice de Martonne para la montaña de Riaño}

\begin{tabular}{lrcc} 
Observatorios & \multicolumn{1}{c}{$\mathrm{I}_{\mathrm{y}}$} & Años-Series & Datos anuales despreciados \\
\hline La Robla & 40,91 & $1969-1987$ & $1969 \mathrm{y} 1987$ \\
Boñar & 49,21 & $1961-1986$ & $1980 \mathrm{y} 1981$ \\
Riaño & 70,99 & $1961-1984$ & Ninguno \\
Priorio & 64,91 & $1961-1987$ & 1987 \\
Isoba & 107,09 & $1961-1971$ & $1961 \mathrm{y} 1971$ \\
\hline
\end{tabular}

Fuente: Centro Meteorológico deł Duero y elaboración propia.

La frecuencia y el volumen de las precipitaciones en forma sólida, así como el tiempo de permanencia de la nieve en el suelo es lo que mejor diferencia las áreas más altas de las más bajas. Aunque en estas montañas no hay ningún mes seco-carencia de aridez estival-, no debe pasar desapercibida la ligera subsequía que se produce en los meses de julio y agosto. Las temperaturas utilizadas en los gráficos de la pág. 161 corresponden a los observatorios de Boñar y Riaño del siguiente cuadro.

Media de las temperaturas máximas y minimas

\begin{tabular}{lcccccccccccc}
\hline & E & F & M & A & My & J & J1 & A & S & O & N & D \\
\hline Riaño & 1,15 & 2,41 & 4,15 & 6,39 & 0,45 & 13,45 & 16,14 & 15,76 & 13,41 & 9,52 & 4,66 & 1,81 \\
Isoba & $-0,15$ & $-0,27$ & 0,31 & 3,33 & 5,02 & 10,46 & 13,24 & 12,57 & 11,23 & 7,12 & 3,91 & $-0,23$ \\
La Robla & 2,29 & 3,55 & 5,13 & 7,68 & 10,04 & 14,69 & 17,82 & 17,28 & 14,60 & 10,24 & 5,82 & 3,10 \\
Bonar & 1,42 & 3,33 & 5,37 & 7,79 & 11,07 & 15,47 & 18,83 & 18,03 & 15,34 & 10,59 & 5,63 & 2,46 \\
Prioro & 1,90 & 2,79 & 4,68 & 7,22 & 10,13 & 14,81 & $17,5]$ & 17,53 & 14,32 & 9,69 & 5,23 & 2,25 \\
\hline
\end{tabular}

Fuente: Centro Meteorológico del Duero y elaboración propia.

2 El índice de Martonme se olyticne asi: $\mathrm{I}=\mathrm{P} / \mathrm{T}+10$. Tal que $\mathrm{P}$ significa precipitación media anual y T la temperatura media anual. Ofrece valores tarıto más pequeños cuanto mayor sea la aridez. Si es menor ‘fue 5 el clima és desértico y cuando está comprendido entre 5 y 20 se denomina scmiárido. 
La temperatura media estimada con los datos del periodo 1961-1987 coincide, casi exactamente, con los facilitados por el Anuario Estadístico de España para el año de 1858.

Los terrenos de las montañas estaban situados en su immensa mayoria entre los 1.000 y los 1.500 metros (véase el siguiente cuadro).

Situación de los terrenos según su altitud en la montaña de Riaño

Metros snbre el nivel del mar

$<1.000$ de 1.000 a 1.500 de 1.500 a $2.000>2.000$

$\begin{array}{lllll}\% \text { sobre el Total } & 13,79 & 71,39 & 14,32 & 0,12\end{array}$

El Anuario denominaba región subalpina, dentro de la zona septentrional del pas, a la "región de coniferas, boj y pastos de sierra», comprendiendo los declives situados desde 850 metros hasta los 1.420 metros. La temperatura de esta región podría computarse -según el Anuario- de « +90 a $+6 "$ ? . Para la región alpina, con pendientes comprendidas entre los 1.420 metros y los 2.000 metros, la temperatura va de $+6^{\circ}$ á $+2^{\circ} ?^{4}$

La fuente anterior al Anuario Estadístico de España que nos proporciona información es el Diccionario de Pascual Madoz, con fecha entre 1845 y 1850. Las preeisiones del Madoz no se pueden comparar" a los datos que ofrece la "Gaceta de Madrid». Pero la información de la Gaceta no aporta nada sobre la región que nos importa. Las series de manchas solares y de pluviosidad recogidas por Albert Carreras en el libro "Estadísticas históricas de España, siglos XIX y XX”, tampoco resuelven el problema de la obtención de datos para la Montaña de Riaño, en la Edad Moderna.

Las páginas del Anuario Estadístico podrían incitar a la utilización de las series climáticas de Ios Alpes, que para los siglos modernos elaboró Christian Pfister. Es evidente que nada sabían en 1859 del trabajo que Pfister publicaría en 1985. Pero, las páginas del Anuario sugerían que "las regiones subalpina. alpina y nevada coinciden casi completamente con el clima de las regiones respectivas de los Alpes». Sigue el redactor del Aruario puntualizando que «sin

- Es la media que se obtiene entre las medias de las temperacuras máximas y las medias de las temperaturas mínimas.

+ La región nevada, *región de las yerbas y prados alpinos, a 2.000 suetros lenía una temperautura de $+2^{2}$, a ...? Véase Antuaro Estodistico de Espaina, 1854, 110. 
embargo, el invierno no es tan frío, pero se cree que nieva tanto en unos puntos como en otros. Eso mismo se piensa en nuestros días de un modo intuitivo. Pero no creo acertado, por el momento, tomar los datos de latitudes suizas para aplicarlos al Noroeste hispano.

Las referencias de Madoz sólo ayudan a confirmar la idea preconcebida que sobre un clima de alta montaña se puede tener. De los doscientos cincuenta pueblos, no todos aportan información climatológica, pero entre los que sí comunican alguna idea podemos clasificar cinco tipos de respuestas:

- aunque algo húmedo es bastante sano.

- templado pero sano.

- frío pero bastante sano.

- frío y nevoso pero sano.

- sumamente frío.

Uno de los mayores apoyos que recibe la comparación del clima montañés con el de los Alpes se encuentra en la respaesta del lugar de Argovejo: "frío y nevoso en seis meses del año y bastante templado los restantes».

Las enfermedades más comunes, según Madoz, eran constipados, fiebres catarrales y tercianas; pulmonías y reumas; dolores de costado ... En Soto de Valdeón hablaban de hidropesía y en Balbuena de fluxiones. Cabe destacar la afirmación sobre Cistierna, «templado y muy sano pues apenas se conoce enfermedad común». La información sobre Barniedo, donde «se daban catarros y pulmonías producidos por la estación», no ilustra mucho más que las anteriores y no aclara de qué estación se trata.

\section{4.-Derechos de propiedad}

Richard Herr señalaba que, en España, allí donde la mayor parte de la tierra pertenecía al municipio era preciso el espíritu comunitario y el gobierno democrático [HERR, 1988, 85]. También mencionaba Herr los benéficos efectos de la propiedad privada. Si dicha propiedad hubiera estado unida a una estructura institucional diferente, habría promovido los necesarios incentivos para el crecimiento económico. Pero la situación resultante fue de estancamiento, tanto para España ${ }^{5}$, como para la Montaña de Riaño.

${ }^{5}$ La ineficacia de la organización económica esfañola durante el Antiguo Régimen tuvo como resultado el estancamiento. Véase Gonzalo ANES, 1979, 159-163, y NORTH/THOMAS, 1988. 
La incidencia, en los concejos, de una modalidad de autogobierno democrático parece haberse mantenido, durante el Antiguo Régimen, con un recio espíritu comunitario. Lo cual parece muy necesario en una región que contaba, en el setenta por ciento de sus treinta y una demarcaciones (es decir con 21), con el Comín como el mayor propietario territorial de aquellos lugares.

En el * concejo abierto* (asamblea convocada al toque de campana) se tomaban las decisiones y se hacian los acuerdos que conformaban el contenido de sus ordenanzas. En estos textos-ordenanzas- se encuentran recogidos los derechos de propiedad (property rights) que eran respetados cuidadosamente por los lugareños. De no orientar s1. conducta, en cualquiera de las actividades reguladas, ajustándola a lo mandado en las ordenanzas, se verían perseguidos y sancionados con las penas establecidas ad hoc.

La estructura de estos derechos incluía, sobre todo, los costes derivados de la emigración trashumante (unos siete meses fuera de casa, normalmente en tierras extremeñas), además de la emigración definitiva. Esto ocurría de esta manera puesto que el objetivo prioritario, para lograr una asignación eficiente de los recursos, era el de alcanzar la más elevada tasa de ocupación posible en cada explotación (familiar, vecino). Desde luego, no consistía en perseguir los mayores beneficios.

Los derechos de propiedad sobre la cesión de ganados en aparcería, más conocido en otros lugares como "comuña o también por el sistema de ir "a me dias", 0, también a "pérdidas y ganancias", se vieron frecuentemente sometidos a los intereses concejiles de cada valle.

Los vecinos del concejo de Valdeón, entre otros, ordenaban en 1766 que nadie pudiese tomar en alparcería ganados forasteros si quedaban libres para dicha cesión bestias propiedad de vecinos [seglares o eclesiásticos] de los lugares del valle. Con esta manera de ajustarse a los condicionamientos del habitat, para qué plantearse esfuerzos dedicados a especializarse en las producciones animales. A no ser, como sucedía con las Cofradías o Capellanías, por motivos de «caridad cristiana».

Queda claro, por tanto, la ausencia de un móvil de acumulación, por parte de las unidades de producción (vecino = familia). Estas unidades productivas practicaban, en los acuerdos del «concejo abierto» (1 voto/vecino; $1 / 2$ voto/ viuda) una estrecha vigilancia acerca de la regulación de la presión de la población sobre los recursos. 
Con la denominación de "gentes de León a un lado", se agrupaba a los montañeses dentro de un conjunto, al que ignoro si todos ellos tenían conciencia de pertenecer ${ }^{6}$. Los vecinos de cada uno de los concejos sí que poseían una certera conciencia de pertenecer a sus respectivas comunidades. Recordemos que bajo las ordenanzas concejiles quedaba regulada la inmensa mayoría de sus actividades cotidianas. Los acuerdos se tomaban, sobre cualquier asunto, en concejo abierto. Para ello, los puntos a tratar se sometían a la votación de los representantes familiares. Un voto por vecino y medio por viuda fue la norma más corriente, aunque, a veces, se concediera a estas últimas el voto íntegro.

Las características que nos permiten considerar a los habitantes de la Montaña de Riaño como una agrupación homogénea son dos:

- La estructura socioprofesional.

- La desigualdad de las rentas.

Composición de la población activa

\begin{tabular}{lcc}
\hline & 1755 & 1786 \\
\hline Labradores & 7.522 & 5.821 \\
Pastores & 766 & 975 \\
Fabricantes y artesanos & 241 & 127 \\
\hline
\end{tabular}

Fuente: A.H.N., sec, Hac., 7457 (G) y B.R.A.H. Censo de Floridablance, ms, 9/6229-6232 (I_é́m, J-IV).

Con los datos del cuadro anterior podemos afirmar que la población de estas montañas estaba constituida en su inmensa mayoría por agricultores. Esta ocupación predominante abarca la pastoría de sus ganados, mientras que los activos que se dedicaban a la trashumancia vienen en la categoría "pastores». El peso de la actividad manufacturera era irrelevante dentro de la actividad económica principal. La crianza y la labranza configuraban la agricultura montañesa que perduraría en aquellas latitudes a lo largo de los tiempos modernos.

\footnotetext{
Acerca de la denominación "gentes de León a un lado» puede consultarse LóPEZ MORÁN, 1984, 15.

La definición de los sociológicos HORTON y HUNT, 1976, 174, acerca de grupo es la siguiente: e Los grupos son agregados en los que los individuos que los forman, tienen conciencia de pertenencia y de interaccións.
} 
Las posibilidades de cuantificación de las rentas, perıniten averiguar los niveles de desigualdad existentes en la Montaña de Riaño?

El interés que perseguimos se limita, según las posibilidades de cuantificación, a los niveles de desigualdad existentes entre los difer'entes ingresos salariales (imputados) para el año de 1755, así como el de las rentas agrarias para el año de 1799.

En ambos casos $[1755 ; 1799]$, para medir la desigualdad se ha utilizado un índice de desigualdad de orden-1, puesto que dicho índice supone una fuerte mejora con relación a los índices convencionales como el de Gini o Lorenz.

Las rentas salariales pertenecientes a las diferentes ramas de actividad nos proveen de las retribuciones del factor de producción trabajo. El total de la renta de los «concejos» (véase cuadro desigualdad, pág. 168) procede de la estimación de las remuneraciones, para las diferentes categorías profesionales de los artesanos: maestro, oficial y aprendiz. A su vez, estas poseen diferentes valoraciones del salario diario recibido. Pcro, para los labradores y los pastores -incluidos sus hijos con más de 18 años-, únicamente abarca su jormal diario. también con diversas valoraciones. El salario diario atribuido a los campesinos, que no suelen ser asalariados, se puede interpretar como sinónimo de la utilidad obtenida por día trabajado.

Los resultados de la desigualdad total (véase pág. 168) deben entenderse como la suma de la desigualdad en los concejos y la desigualdad entre los concejos. La primera es 0,033548 , y la última 0,041357. Por consiguiente la desigualdad total es 0,0749054 .

La desigualdad entre las rentas saiariales de los concejos sobrepasa ligeramente la que existe en el interior de los mismos. La cota inferior de la desigualdad total sería 0 , evidentemente, y la cota superior 2,688739 . Una vez conocidos los extremos, la desigualdad total parece secundar, muy favorablemente, la hipótesis de la obstrucción al crecimiento económico. Cabría retomar, ahora, los débiles niveles alcanzados por la renta per-cápita para confirmar el marco de la pobreza fiscal con el que ellos mismos suelen retratarse en los documentos conservados.

7 La fuente principa] empleada para obtener los ingresos salariales son los *Mapas Generales* del Gatastro de Ensenada, con fecha del año de 1755. Se utilizará, también, otra fuerte: el «Repartimiento de Contribución directa para el año de 1814», que nos ofrece la renta bruta agraria e industrial de cada demarcación para el año de 1799. Ambas fuentes tienen en común el objetivo fiscal de su elaboración. Sobre la desigualdad, véase PÉREZ/LÓPEZ, 1990. 
Acerca de la desigualdad entre las rentas de los concejos, para el año de 1799, hemos obtenido un 0,041308. Este guarismo coincide, casi en su totalidad, con la cifra de desigualdad de las rentas salariales del año de 1755. Para el último año del siglo, la cota superior del índice -1 que nos mide la desigualdad, es 2,622631. Por lo tanto, a finales de la centuria se ve reforzada la idea de un reparto muy igualitario de las retribuciones del factor de producción capital, entre los concejos. Después de todo, con estos últimos datos se puede convenir, con más fuerza, la existencia del estancamiento económico de la Montaña de Riaño.

Si los Austrias o los Borbones hubieran dirigido hacia la región inversiones para la mejora de las comunicaciones, no cabe duda de que tales decisiones habrían afectado la distribución de las rentas salariales imputadas. Mas, por desgracia, las monarquías no autorizaron un gasto estatal que podamos tener en consideración. Así que se puede aceptar dicha inversión como nula. El camino carretero del puerto seco de Pajares y la carretera «Sahagún-Ribadesella que atravesarían las montañas hacia el mar Cantábrico no se terminaron hasta el año 1834, el primero, y la segunda seguía construyéndose, aún en 1885.

Sin duda el estancamiento en el que se encontraban estos trabajos públicos reafirma la existencia de una igualdad mantenida al reducidísimo nivel que expresan los ingresos salariales por concejo.

Ahora, observemos lo sucedido con la influencia ejercida por el marco institucional sobre la desigualdad en la región (véase cuadro desigualdad). Se percibe la ausencia de cualesquiera relación entre la superación del nivel de desigualdad 0,033548 -el que sintetiza la desigualdad que existe en cada concejopor las demarcaciones estudiadas y su respectiva pertenencia al realengo, a los señoríos laicos, a los señoríos eclesiásticos, tanto como las que poseían «jurisdicción propia».

La pobreza fiscal que los montañeses declararon en un sinnúmero de ocasiones, encuentra su contrastación favorable en la renta per-cápita regional. La renta per-capita de la Montaña de Riaño, hacia la mitad del siglo XVIII, ubicaba a esta región en el área de aquellas -submeseta norte del Duero, Galicia- que registraban las más débiles productividades del trabajo. En oposición a las regiones del Sur de la Corona de Castilla, donde se sobrepasaba, ampliamente, la media global de 296,5 reales (Grupo'75, 1977). Los 172,89 reales de vellón por habitante de la Montaña superaban holgadamente los 123,9 reales de Galicia, pero no alcanzaban el nivel medio para toda la región leonesa (Reino de León más Asturias), de unos 240,2 reales. 


\begin{tabular}{|c|c|c|c|c|c|c|}
\hline \multirow[b]{2}{*}{ Concejos } & \multirow{2}{*}{$\begin{array}{c}\begin{array}{c}\text { Renita } \\
\text { total }\end{array} \\
\text { Rs. Vn. }\end{array}$} & \multirow{2}{*}{$\begin{array}{l}\text { Poblac. } \\
\text { activa } \\
\text { Vecinos }\end{array}$} & \multirow{2}{*}{$\begin{array}{l}\text { Habi- } \\
\text { tantes }\end{array}$} & \multirow{2}{*}{$\begin{array}{c}\begin{array}{c}\text { Rental } \\
\text { habit. }\end{array} \\
\text { (en Rs. de Vn.) }\end{array}$} & \multirow{2}{*}{\multicolumn{2}{|c|}{$\begin{array}{c}\text { Desigualdad } \\
\text { en los } \\
\text { «concejos* }\end{array}$}} \\
\hline & & & & & & \\
\hline Pueblos de León y su Jurisdicción & 39.700 & 162 & 592,92 & 66,96 & $0,000699 \mathrm{R}$ & $\mathrm{R}$ \\
\hline Concejo de Fenar & 84.000 & 174 & 636,84 & 131,90 & $0,000782 \mathrm{R}$ & $\mathrm{R}$ \\
\hline Concejo de Vegacervera & 214.590 & 442 & $1.617,72$ & 132,65 & $0,009249 \quad \mathrm{~S}$ & $S E$ \\
\hline Concejo de Gordón & 123.740 & 477 & $1.745,82$ & 70,88 & $0,006514 \mathrm{~S}$ & \\
\hline Concejo de Arbas & 74.020 & 216 & 790,56 & 93,63 & $0,049904 \mathrm{R}$ & \\
\hline Concejo de La Tercia de] Camino & 124.500 & 259 & 947,94 & 131,34 & $0,000025 \mathrm{R}$ & $\mathrm{R}$ \\
\hline Concejo de La Mediana de Argïello & 128.840 & 426 & $1.559,16$ & 82,63 & $0,039630 \mathrm{R}$ & R \\
\hline Concejo de Valdelugueros & 92.220 & 223 & 816,18 & 112,99 & $0,003902 \mathrm{R}$ & $\mathrm{R}$ \\
\hline Concejo de Peñamián & 114.670 & 331 & $1.211,46$ & 94,65 & $0,019445 \mathrm{R}$ & $\mathrm{R}$ \\
\hline Concejo de Redipollos & 66.660 & 226 & 827,16 & 80,59 & $0,011006 \mathrm{P}$ & $\mathrm{R}$ \\
\hline Jurisdicción de Bonat & 137,700 & 320 & $1.171,2$ & 117,57 & $0,023417 \mathrm{~S}$ & $\mathrm{~S}$ \\
\hline Jurisdic. Real de La Vega de Boñar & 82.310 & 214 & 783,24 & 105,09 & $0,114977 \mathrm{~S}$ & SE \\
\hline Conc de Las Arrindardas y sus lugares & 25.990 & 65 & 237,9 & 109,25 & & $\mathrm{SE}$ \\
\hline Condado de Colle & 50.760 & 113 & 413,58 & 122,73 & $0,012679 \mathrm{~s}$ & SE \\
\hline La Encartación de Curueño & 119.300 & 250 & 915 & 130,38 & $0,004145 \mathrm{~S}$ & S \\
\hline Concejo de Valle de Curueño & 196.710 & 403 & $1.474,98$ & 139,36 & $0,000465 \quad 8$ & \\
\hline Concejo de Rivesla & 31.440 & 72 & 263.52 & 119,31 & $0,073077 \mathrm{~S}$ & \\
\hline Concejo de Valderrueda & 163.320 & 507 & $1.855,62$ & 88,01 & $0,089085 \mathrm{~S}$ & S \\
\hline Concejo de Valdoré & 42,900 & 140 & 512.4 & 83,72 & $0,011620 \quad 8$ & 8 \\
\hline Concejo de Modino & 62.160 & 147 & 538,02 & 115,53 & $0,090702 \mathrm{R}$ & $\mathrm{R}$ \\
\hline Concejo de Valdetuéjar & 104.370 & 341 & $1.248,06$ & 83,63 & $0,037197,8$ & S \\
\hline Concejo de la Guzpeña & 28.800 & 80 & 292,8 & 98,36 & $0,000000 \mathrm{~S}$ & S \\
\hline Concejo de Valdellorma & 88.320 & 183 & 669,78 & 131,86 & 0,0005738 & 8 \\
\hline Jurisdicción de Tierra de la Reina & 187,300 & 46.3 & $1.694,58$ & 110.59 & $0,001399 \mathrm{~s}$ & $\mathrm{~S}$ \\
\hline Concejo de Valdeburón & 154.220 & 535 & $1,958,1$ & 78,76 & 0,040307 s & 8 \\
\hline Concejo de Valdeón y sus lugares & 93.020 & 224 & 819,84 & 113,46 & & $\mathrm{~S}$ \\
\hline Concejo dr Alcón & 68,920 & 2.35 & 860,1 & 80,13 & $0,066808 \quad \mathrm{R}$ & $\mathrm{R}$ \\
\hline Concejo de Sajambre & 56.100 & 178 & 651,48 & 86,11 & & $\mathrm{R}$ \\
\hline Concejo de Yantanillo & 24.660 & 72 & 263,52 & 93,58 & $0,001453 \quad \mathrm{~S}$ & $\mathrm{SE}$ \\
\hline Concejo de Urbayos & 30.380 & 100 & 366 & 83,01 & $0,024997 \mathrm{~s}$ & \\
\hline Sumau los ługares de Jurisdic. propir & 374.410 & 1.122 & $4.106,52$ & 91,17 & 0,060336 & \\
\hline TOTALES & 3.186 .030 & 8.700 & 31.842 & 100,0574 & & \\
\hline & & & DFGICU & $\mathrm{DADTOT}$ & & \\
\hline
\end{tabular}

La desigualdad entre Concejos (Interconcejil $)=0,041357$.

Desigualdad = Desigualklad Interconcejil + Desigualdad Intraconcejil * $(\mathrm{N} / \mathrm{N}) *(\mathrm{M} / \mathrm{Mc})$.

Siendo $\mathrm{Ne}=$ múmero de halitantes de cada concejo $/ \mathrm{N}=$ número hajitantes de ioda la nontañu.

$\mathrm{N}=$ renta nedia/habitante de toda la monteña/ Mc = renta media/habitante de cada concejo.

$\mathrm{R}=$ Realengo/ $\mathrm{S}=$ Señorío laico/ $/ \mathrm{SE}=$ Sectorío Eclesí́atico. 
Las fluctuaciones estacionales de los óbitos que comentaremos aquí, son las de cinco lugares de las montañas leonesas, durante los siglos XVII, XVIII y primera mitad del siglo XIX. Nuestro estudio se concreta en estas cinco parroquias debido a los límites impuestos por las fuentes disponibles. Como muchos trabajos de historia local, éste de una región de alta montaña, se ha encontrado con serias dificultades para hallar dichas fuentes.

Las cinco parroquias -Boñar, Riaño, Puebla de Lillo, Vegamián y Voznuevo- nos parecen representativas del conjunto regional, tanto por ubicación como por el tamaño de sus efectivos poblacionales ${ }^{8}$. Dos de ellas, Boñar y Riaño, servirán para la comparación de los ritmos vitales con otras dos parroquias de las llanaras leonesas, Destriana-Jiménez y La Bañeza. Así como las cinco, en conjunto, representarán a las montañas leonesas para compararlas a la representación de parroquias rurales que integran la «España interior»".

Los rasgos esenciales del ciclo que siguen las muertes en las montañas corresponden a un marco geográfico bien diferenciado del resto ${ }^{10}$. La denominada Montaña de Riaño forma parte de la cordillera que bordea la actual región castellano-leonesa. Además, no debemos olvidar que los gráficos reflejarán las características de la estacionalidad de las defunciones que pertenecen a un grupo rural muy homogéneo: los labriegos de las montañas leonesas".

Con ello pretendemos responder a una necesidad que Lorenzo del Panta había puesto de manifiesto, ya en 1987. Me refiero a considerar los estudios de mortalidad diferencial, tanto en términos geográficos como en lo referente a las condiciones socio-económicas o espaciales ${ }^{12}$.

* En 1787 (la fecha con datos más fiables, debido a la fiuilidd no fiscal del recuento de Floridablanca [véase DOPICO/ROWLAND, 1990]), Boñar (nús su anejo, La Vega) y Riaño (más su ancjo, La Puerta) contaban con 409 y 512 habitantes. En la misma fecha Destriana-Jiménez y La Bañeza sumaban 259 y 453 habitantes, respectivamente (RUBIO/PÉREZ, 1987, 67).

Las parroquias que utiliza Pérez Morcrla corresponden a siete localidades [para párvulos, 0-7 anos; y adultos]: Chiloeches, Sobradillo, Otero de I lerreros, Medias de Manticl, Ciereceda, Barajas de Melo y Villavieja de Yeltes. Esta muestra corresponde a cuato provincias actuales: dos localidades a Salamoncia, trés a Guadalajara, una a Segovia y otra a Cuenea. Véase PÉREZ MOREDA, $1980,205-208$.

10 Al no emplear el método de reconstrucción de familias no trataremos de la mortalidad es1acional por grupos de edades. Podría aportar los datos del Censo de Floridahlanca, para 1786, con su particular clasificación por edades, pero no lo he creido oporumo.

1 La región es la Montaña de Riaño que incluye los partidos judiciales de Riaño y la Vecilla.

12 Del Panta indica además de las referidas condiciones geográficas, espaciales y socio-econúmicas, las causas de muerte. Véase DEL PANTA, 1987. Las cansas de muerte no se tratarán en este trabajo. Otros han intentado antes responder a esas necesidades de la demografía diferencial, por ejenplo, DOMINGO PÉREZ, 1990, 1,103-1.133. 
Se ha obviado describir la evolución de los efectivos poblacionales para cenuarnos sobre el análisis de la trayectoria estacional que presentaban las defunciones a lo largo del año, durante los siglos XVII, XVIII y primera mitad del siglo XIX.

Parece necesario empezar justificando cómo la mortalidad epidémica puede despreciarse, dentro del ámbito montañés, debido a la magnitud de las perturbaciones estacionales que hubiera producido su influjo. La razón es bien sencilla, no se produjeron crisis de sobremortalidad que merezcan, durante el Antiguo Régimen, mayor califica tivo que fuertes según el método de Dupâquier (TASCON, 1991,721)

La única epidemia que asoló la región con posibilidad de ser considerada como catastrófica fue la peste de 1596-1602, de la que han quedado escasísimos testimonios. Otras causas que motivaban grandes mortandades, además de la peste, como por ejemplo la guerra y el hambre también se dieron cita en las montañas. Pero la proporción de sus consecuencias no fue nunca catastrófica. La ausencia de grandes crisis de sobremortalidad se debió en buena medida a los modos de vida desarrollados entre las altas montañas.

Las hambres se mitigaban mejor resguardados en aquellos valles que en las llanuras. Los montañeses habían convertido en obligación, desde siempre, cultivar un amplio espectro de plantas. Aparte, claro, de arrancar hierbas salvajes y criar cerdos, terneros y ovejas que completaban la alimentación, compensando muchas veces la carencia de pan (TASCON, 1991, 599-6.082).

La guerra de la Independencia y la primera Guerra Carlista tuvieron una escasa incidencia en las montañas. Las principales crisis de mortalidad se produjeron en $1698-99,1763-65,1770-72,1804-05,1809-12$ y $1832-34$.

Los datos mensuales se han agrupado por períodos largos, de cincuenta años, en todas las ocasiones en que los datos disponibles lo han permitido. La comparación con los pueblos de las llanuras se ha realizado respetando la agrupación antedicha. He creído más conveniente presentar los gráficos de este modo que adaptar los períodos de la montaña según la presentación que ofrece RUBIO PEREZ (1987) para los datos de las llanuras. De todas formas las diferencias se comprueban mejor así, puesto que no tiene por qué darse una coincidencia total entre la estacionalidad de las defunciones en cada siglo' ${ }^{14}$.

3 En la clasificación de Bupâquier después de la mencionada magnitud, aún quedan las de *crisis importante», «gran crisiss y kcatástrofe».

i4 Para las llanuras leonesas RIBIO PEREZ, 1987, ha enlazado las series que comienzan en la segunda nutad del siglo XVII con la primera mitad del siglo XVIII. En las montañas, clesde luego, no existe una coincidencia total entre la estacionalidad de los óbitos durante esos nismos períodos. 
La desigual duración de los meses del año obligaría a tomar un valor convencional, aplicable a todos, para corregir los datos brutos cuando se estimasen los porcentajes de desviación mensuales. Pero no se ha modificado ese número variable de días debido a la imposibilidad de alteraciones notables en los resultados atribuibles a la falta de corrección de los datos originales ${ }^{15}$.

Los análisis por separado del movimiento estacional de las defunciones de adultos y de párvulos [0-8 años] sólo han sido posibles para los siglos XVIII y XIX. Por supuesto, esto se debe a la tardía aparición de la especificación "párvulos» en los asientos de los libros sacramentales.

\section{1.-Defunciones de párvulos}

Los libros sacramentales de difuntos de las parroquias no contienen, como es bien sabido, todos los niños que morían entonces. Los asientos de los entierros de párvulos empiezan a incluir a los mismos sólo a partir del siglo XVIII. Con anterioridad al setecientos no se encuentra dicha especificación.

La infravaloración del número de fínados corresponde, casi totalmente, a la ocultación de los niños difuntos con escasas horas de vida. El infanticidio y los abortos tampoco se reflejan en los libros sacramentales ${ }^{16}$.

Las cuatro listas de confirmados de la parroquia de Lillo han servido para cruzarlas con los bautizados de la parroquia, rastreando la existencia de estos últimos. Assí hemos conocido los párvulos y niños de una generación que sobrevivieron hasta cierta edad, durante el siglo XVIII. Este método refuerza la idea, ya muy contrastada, de que los riesgos de fallecer para los recién nacidos, en el Antiguo Régimen, son más elevados cuanto más cerca del parto.

En la subsistencia de aquellos niños influyó severamente la desnutrición de las madres, pues los infantes «mamaban la teta» hasta los dos años de edad, e incluso más. En la desnutrición de las progenitoras, así como en la de los destetados, se tuvo que notar la carencia de proteínas animales que provenían en su mayor parte de la leche de ovejas, cabras o vacas. La razón de aquel descenso proteínico en la leche de animales domésticos se debería a la influencia del clima. Como es conocido, desde finales del siglo XVI hasta finales del siglo XIX,

is Máxime si tenemos en cuenta la señalada ausencia de crisis de sobremortalidad catastróficas para todo el período.

${ }_{16}$ Es de sobra conocida la importancia de las muertes entre 0 y 1 años de vida. Más importante que los tramos de edad subsiguientes, de 1 a 4 y de 5 a 9 años. Véase p.e., para Asturias en el siglo XIX, TASCON, 1990, 453. 
el clima experimentó un cambio en toda Europa que, también debió afectar a la península -the «Little Ice Age: 1550-1850-, sucediéndose inviemos muy fríos, seguidos de primaveras frescas y veranos húmedos ${ }^{17}$.

Las condiciones climáticas descritas, en la medida que se dieron, redujeron el contenido proteínico del heno. Por lo que, a finales del siglo XVII y principios del XVIII, a los párvulus les fue relativamente mús difícil seguir vivierdo, una vez consumado el destete que durante el período de lactancia. La comprobación que nos facilitan las listas de confirmados habla en favor de estas hipótesis, así como la extensión de su aplicación a tuda la Montána de Riaño.

En la parroquia de Boñar el otoño y el invierno muestran efectos más letales sobre los párvulos que la primavera, desde 1700 a 1850 . Sólo cabe destacar para el período 1750-99 el máximo alcanzado en abril, al que siguen inmediatamente un segundo máximo en diciembre y un tercero en octubre y enero (véanse gráficos, pág. 179). Es decir que se daba una gran sensibilidad al frío en las montañas con relación á las muertes infantiles.

En Riaño, desde 1757 a 1850 , la estación otoño-invernal se afirma tamhién como la de efectos más destructivos. Fin el período 1757-99 el tercer máximo se reparte entre enero y mayo. Para 1800-1850 la primavera muestra su poder letal con mayor entidad y comparten el máximo pico de la curva estacional marzo y septiembre (véanse gráficos, pág. 179). De todos modos se confirma lo decisivo del clima, para la salud de los párvulos, influyendo en las váriaciones estacionales de la mortalidad endógena, tanto como de la exógena ${ }^{18}$. A las escasas condiciones higiéricias de la éjoca hay que añadirle el efecto del descenso de las temperaturas en la segunda mitad del año.

I a comparación entre las series de Boñar y las de Destriana-Jiménez evidencia una fluctuación progresiva del otoño, desde el siglo XVII a la mitad del siglo XIX, hasta llegar a afirmarse como la estación más letal para los niños en las llanuras (véanse gráficos, pág. 180).

No por ello pierde intensidad la mencionada relación entre muertes infantiles y bajas temperaturas otroño-invernales en las montañas. Ahora bien, llegados a la primera mitad del ochocientos, la proporción de los óbitos en otoño es

17 Véase, rQuaternary Climate in Western Mcditerranean , Ed. F. López-Vera, U.A.M.. 1986. Cit. en CORELLA SUÁREZ, Pilar (1988): *Aspectos fiscules de la rentá de la nieve en la Coroua de Ciastilla durante los siglos XVII y XVIII. Monedas y Ciédito, n. 184 (marzo), pág. 47-60.

1* Mortalidad endógena: anonalías congénitas, lesiones de origen obstétrico y alecciones de] recién uaciclo. Mortálidad exógena: enfermedacles infecciosas o parasitarias, accidentes, cnvenenamiencos o tramatismos. Las tuentes parroquiales, el nuestro caso, no permiten distinguirlas. 
menor que en las llamuras (véanse gráficos, pág. 180). Los cambios térmicos de la primavera terminarían por convertirse llegados al ochocientos, en los más perniciosos para la salud de los párvulos montañeses. Al mismo tiempo que, desde el siglo XVII (1660) la primavera en las llamuras leonesas va perdiendo influencia en las muertes infantiles. Dicha influencia la recogerá el otoño.

El final del verano junto al otoño ejercen, en la zona llana -la Bañeza-, un claro predominio como épocas más letales del año. Así sucedía durante la centuria del setecientos y la primera mitad del siglo XIX. Durante ese período se perfila un cambio en la amplitud de las variaciones que experimenta la mortalidad en el espacio montañés.

En las montañas no se alcanzarán durante el período 1800-1850 las cotas más altas de mortalidad de la etapa anterior, situadas en los meses de septiembre y octubre. Aín así, septiembre se repartirá el poder letal con marzo. La sensibilidad al frío no ofrece duda alguna, a tenor de las defunciones registradas en los meses invernales que ganan peso en el siglo XIX respecto a 1757-1799; y se distancian más de las defunciones ocurridas durante esos meses en las llanuras.

\section{2.-Defunciones de adultos}

La parroquia de Boñar experimentó una estacionalidad de las defunciones de adultos para el siglo XVIII y la primera mitad del siglo XIX, con un fortísimo carácter otoño-invernal. Si exceptuamos el período 1800-1850, desde 1660 a 1799 , el ascenso de las temperaturas primaverales provoca un crecimiento paralelo de las defunciones de adultos. La fluctuación se iniciaba en marzo y culminaba en mayo. El número de óbitos en primavera seguía en importancia a los del otoño-invierno (véanse gráficos, pág. 181).

La primavera en Riaño presenta invertida la progresión de las defunciones de adultos, según el período considerado. En el período 1750-1799, los óbitos ascienden de marzo a mayo para volver a disminuir en el verano. Mientras que en 1800-1850 marzo representa el primer máximo del movimiento estacional, para disminuir hasta mayo y seguir dentro de esos bajos niveles de mortalidad durante el verano.

Los efectos letales del otoño-invierno, entre 1750-1799, fueron igualados en el mes de mayo respecto a enero. Durante el período 1800-1850 marzo aventaja en intensidad los efectos destructivos de septiembre, octubre y noviembre. Abril se situará con un nivel semejante al de noviembre. 
La sensibilidad al frío de los organismos adultos parece endurecerse en el transcurso de la mitad del setecientos a la mitad del siglo XIX. Pero, con el paso del tiempo, en Boñar y en Riaño se agudiza la receptividad a los cambios térmicos -léase subida de temperaturas- producidos durante la primavera, comprobándose un aumento en la proporción de muertes durante dicha estación.

La comparación Boñar/Destriana-Jiménez, así como la de Riaño/La Bañeza, invitan a reflexionar sobre un cambio climático general para la primera mitad del ochocientos. Sobre todo con relación a la incidencia rural de dicho cambio". La reacción al fríg en las montañas sigue su curso habitual, en el que la estación otoño-invernal se cobra el mayor saldo en vidas de adultos. Mientras, en las llanuras se observa la inclusión del mes de agosto entre los de consecuencias más funestas.

El mes de febrero, tanto en Boñar como en Riaño, es el de mayor amplitud en sus variaciones. Por lo cual cabe pensar en fluctuaciones climáticas-térmicas-insalubres que principian en dicho mes y no tanto en las propiamente primaverales. Sin embargo, la tónica de una subida de las temperaturas en primavera se afirma como un factor decisivo para explicar un cambio en la letalidad de dicha estación en áreas rurales.

\section{3.-Comparación con la España interior}

La siguiente comparación tomará en cuenta dos conjuntos, siete parroquias rurales de la España interior respecto a las cinco parroquias de las montañas leonesas ${ }^{20}$ (véanse gráficos, pág. 183).

Se han obtenido las series de estacionalidad del conjunto montañés para la primera y segunta mitad del siglo XVIII y primera del siglo XIX, En estos tres grandes períodos aparece un máximo otoño-invernal para la mortalidad de adultos. De 1750 a 1850 se sitúa un segundo máximo primaveral correspondiente a los meses de mayo [1750-1799] y marzo [1800-1850].

El fuerte carácter letal de la estación otoño-invernal no debe ocultar el papel diferencial de una primavera cada vez más influyente en las defunciones que la soportada por el interior hispano. Cabe resaltar que la primera gran diferencia se centra en el carácter otoño-invernal montañés frente al estivo-otoñal de la mortalidad en el interior.

19 Es necesario puntualizar que la Bañeza es más urbana que el resto de parroquias analizadas (RUBIO PÉREZ, 1987).

Véase PÉREZ MOREDA, 1980, 201-217. 
Con las defunciones infantiles sucede algo parecido. De manera que el máximo otoño-invernal de la mortalidad de adultos se mantiene igual en la de los párvulos montañeses. Unicamente de 1750-1799 se da un segundo máximo primaveral -en abril- y un pequeño tercer máximo en mayo compartido con enero. Para 1800-1850 marzo compartiría ese tercer máximo con octubre.

Por lo tanto, se reafirma el carácter diferencial del movimiento estacional de la mortalidad de párvulos montañesa frente a la del interior español. El fundamento de la estacionalidad en las montañas leonesas es otoño-invernal, mientras que el del interior de España es estivo-otoñal. Sin olvidar el carácter de una primavera mucho más letal en las montañas que en el interior.

La amplitud de las fluctuaciones de la mortalidad infantil, en las montañas, se asemeja mucho a la de los adultos (véanse gráficos, págs. 180, 181 y 182). También, hay que considerar el peso específico de las defunciones de párvulos sobre el total. En la Montaña de Riaño ese peso es bastante inferior, las más de las veces (véase el cuadro siguiente), a ese cincuenta por ciento del total que las defunciones de párvulos suponen en el caso de la España interior. Sin embargo no parece que existieran grandes ocultaciones, tanto por el influjo de la mentalidad católica de sus ordenanzas, como por los registros de bautizados de secorro.

Proporción de párvulos difuntos/total difuntos en las montañas leonesas

\begin{tabular}{lrrrrr}
\hline Períodos & Boñar & Lillo & Riaño & Vegamián & Voznuevo \\
\hline \multicolumn{5}{c}{ (En Porcentaje) } \\
\hline $1700-1749$ & 47,05 & \multicolumn{3}{c}{} & 10,05 \\
$1750-1799$ & 22,05 & 13,65 & 40,52 & 32,72 & 15,09 \\
$1800-1850$ & 23,20 & 1,97 & 39,17 & 40,77 & 31,30 \\
\hline
\end{tabular}

Fuente: Archivos parroquiales de Boñar/Puebla de Lillo/Riaño/Voznuevo; y Archivo Histórico Diocesano de León. Libros de difuntos de las parroquias correspondientes.

En la España interior las similitudes entre la estacionalidad de la mortalidad adulta y la infantil son muy notables. La excepción radica en que tanto el máximo de verano y otoño como el mínimo primaveral son mucho más acusados en el caso de las defunciones de párvulos que la de adultos. Por lo cual la amplitud de la fluctuación anual de la mortalidad de párvulos es notablemente superior a la que se registra entre la mortalidad de las edades 
adultas. Pero en este caso la mortalidad de las edades más jóvenes suponía, como se ha dicho más arriba, cerca del 50 por ciento del total de las defunciones.

La semejanza en la amplitud de las fluctuaciones de la mortalidad infantil y la de adultos no puede achacarse, en las montañas leonesas, al grado de ocultación que encierren los asientos de los párvulos difuntos. La evolución, desde el siglo XVII al XIX, de la tasa neta de reproducción (TNR) confirmaría la característica anterior como diferencial, secundando la falta de ocultaciones imprortantes (TASGON, 1991). Los mínimos primaverales superan notablemente a los de la España interior, salvo el correspondiente al mes de marzo durante la segunda mitad del siglo XVIII. La primavera resultaba, por tanto, más letal en las montañas que en el interior de España.

La ausencia de una mayor amplitud en las fluctuaciones de la mortalidad de los párvulos montañeses permite considerar como reducida la influencia que ejercian las muertes infantiles sobre el movimiento estacional considerado en su conjunto ${ }^{21}$.

Por todo lo cual podemos afirmar que las estructuras tradicionales de la mortalidad en las montañas leonesas ofrecen diferencias importantes respecto al modelo de esquema estacional que, para el conjunto español, of recía SánchezAlbornoz para 186,3. Estas diferencias se manifiestan bien con relación a las llanuras leonesas, tanto como respecto a la España interior. Siempre, eso sí, considerando las comparaciones dentro de un ámbito rural.

Las bajas temperaturas de las montañas ejercían mayor influencia en la mortalidad humana que sobre las muertes registradas, durante los mismos siglos, fuera de ellas (llanuras leonesas y España interior).

La progresión ascendente de las temperaturas primaverales se mostró más letal en las montañas que las consecuencias de ese crecimiento térmico para los habitantes de las llanuras leonesas y castellanas. Probablemente, porque la primavera de las montañas no era sino una prolongación del invierno (como nos relatan las respuestas del Madoz, p.e.), en la cual los organismos seguían acusando una gran sensibilidad al frío.

Durante la primavera persisten las mismas etiologías que constituyen la base de las causas de nuerte en invierno, tanto para adultos como para párvu-

21 El carácter de las crisis, de sobremortalidad de carla períndo fue muy parecido y, aderuás, las más abundantes tuvicron escasa identidad. Es dccir [ueron según el método de Dupâquier exísis menores. Por lo tanto no se observan distorsiones importantes en los perfilen de las curvas de estacionalidad de las defunciones. 
los. En los meses primaverales aumentaba el número de muertos por las enfermedades propias de la estación, tales como el asma y otras broncopatías. La población adulta se moría de enfermedades infecciosas graves, como las pulmonías, pleuresías, fiebres tifoideas y otras fiebres sin filiar. Los párvulos también sufrían las consecuencias de otras enfermedades infecciosas graves, y se morían a consecuencia de la viruela, el sarampión o la tosferina ${ }^{22}$. Entre dichas enfermedades infecciosas adquiría especial importancia, para los meses de septiembre y noviembre el crup -término alusivo a la localización faringea de la difteria-, que incidía en la mortalidad infantil intensamente, antes de que se divulgara la vacuna y los antibióticos.

\section{BIBLIOGRAFÍA}

ANES, Gonzalo (1983): El Antiguo Réginen: los Borbones, Madrid. Alianza Editorial./Alfaguara.

COMISIÓN DE ESTADISTICA GENERAL DEL REINO (1859): Anuario estadistico de España correspondiente al año de 1858. Madrid. Imprenta Nacional.

DEL PANTA, Lorenzo (1987): «Fattori e condizioni della mortalità tra 1800 e 1930: Igiene, salute c ambiente. La situazione in Italias, Boletín de la Asociación de Demogrufía Histórica, n. 2, pág. 41-69.

DOMINGO PÉREZ, Concepción (1990): :Mortalidad diferencial en el País Valenciano», en Preactas del II Congreso de la Asociación de Demografía Histórica. Alicante. Universidad d"Alacant/Caja de Ahorros Provincial de Alicante, pág. 1.103-1.133.

DOPIC(), Fausto/ROWLAND, Robert (1990): "Demografía del Censo de Floridablanca. Una aproximación*, Revista de Historia Económica, n. ${ }^{3}$ (año VIII), pág. 591 618.

GRUPO'75 (1977): La economia del Antiguo Régimen. La aRenta Nacional" de la Corona de Castilla. Madrid. U.A.M.

GUTIÉRREZ ROLDÁN, Héctor G. (1989): "Climat et mortalité différentielle en France au XVIII siècle», Annales de Démographie Historique, n." 50 (novembre), pág. 9-28.

HERR, Richard (1984): Memorias del cura liberal don Jutu Antonio Posse. Con su discurso sobre la constiturión de 1812. Madrid. Siglo XXI de España.

HORTON, Paul B./HUNT, Chester L. (1976): Sociología. Madrid. McGraw-Hill.

LOPEZ MORÁN, Elias (1984): Derecho consuetudinario leonés. León. Diputación Provincial de León.

22 Sobre la causa mortis véase TASCON, 1991, 726-730. 
MAD0Z, Pascual (1983): Diccionario Geográfico-Estadístico-Histórico. León, ed. facsímil del Diccionario Geográfico-Estadístico-Histórico de España y sus posesiones de ultramar, 1845-1850. Valladolid. Editorial Ambito.

NORTH, Douglas C./THOMAS, Robert P. (1988): The rise of the Western World. A New Economic History. Cambridge. Cammbridge University Press.

PÉREZ MOREDA, Vicente (1980): Las crisis de mortalidad en la España interior, siglos XVI-XW. Madrid. Siglo veintiuno edts.

PÉREZ, Rigoberto/LOPEZ, Ana Jesús (1990): «Algunas consideraciones sobre la cuantificación de la desigualdad de la renta. Una aproximación al caso de Asturias», en Actas del II Congreso Asturiano de Sociología. Perlora.

PFISTER, Christian (1986): Klimageschichte der Schweiz, 1525-1860, Band 1/ Band 2, Academia Helvetica», 6/1 \& 6/2, Bern und Stuttgart. Verlag Paul Haupt.

RUBIO PÉREZ, Laureano (1987): La Bañeza y su tierra, 1650-1850. Un modelo de sociedad rural leonesa: Los hombres, los recursos y los compontamientos socia(es). León. Junta de Castilla y León/Servicio de Publicaciones de la Universidad de León.

SÁNCHEZ-ALBORNOZ, Nicolás (1975): *Modernización demográfica. La transformación del ciclo vital anual, 1863-1960*, en Jalones en la modernización de Esparia. Barcelona. Edil. Ariel.

TASGÓN FERNÁNDEZ, Luis Julio (1990): «Enfermedad y muerte en Asturias durante el siglo XIX (I): un ejempla del área central y las zonas periféricas», Boletén rét Instituto de Estudios Asturianos, n. 13.5 , pág. 431-472.

(1991): Una historia de las montañas lconesas, siglos XVI-XX. Oviedo. Servicio de Publicaciones de la Universidad de Oviedo

- (1993): «El estancamiento de las econumías de montaña en España: los valles leoneses de la cordillera cantábrica, en el siglo XVIII», Hsturlis d'Historia Hénómica, cin premsa. 

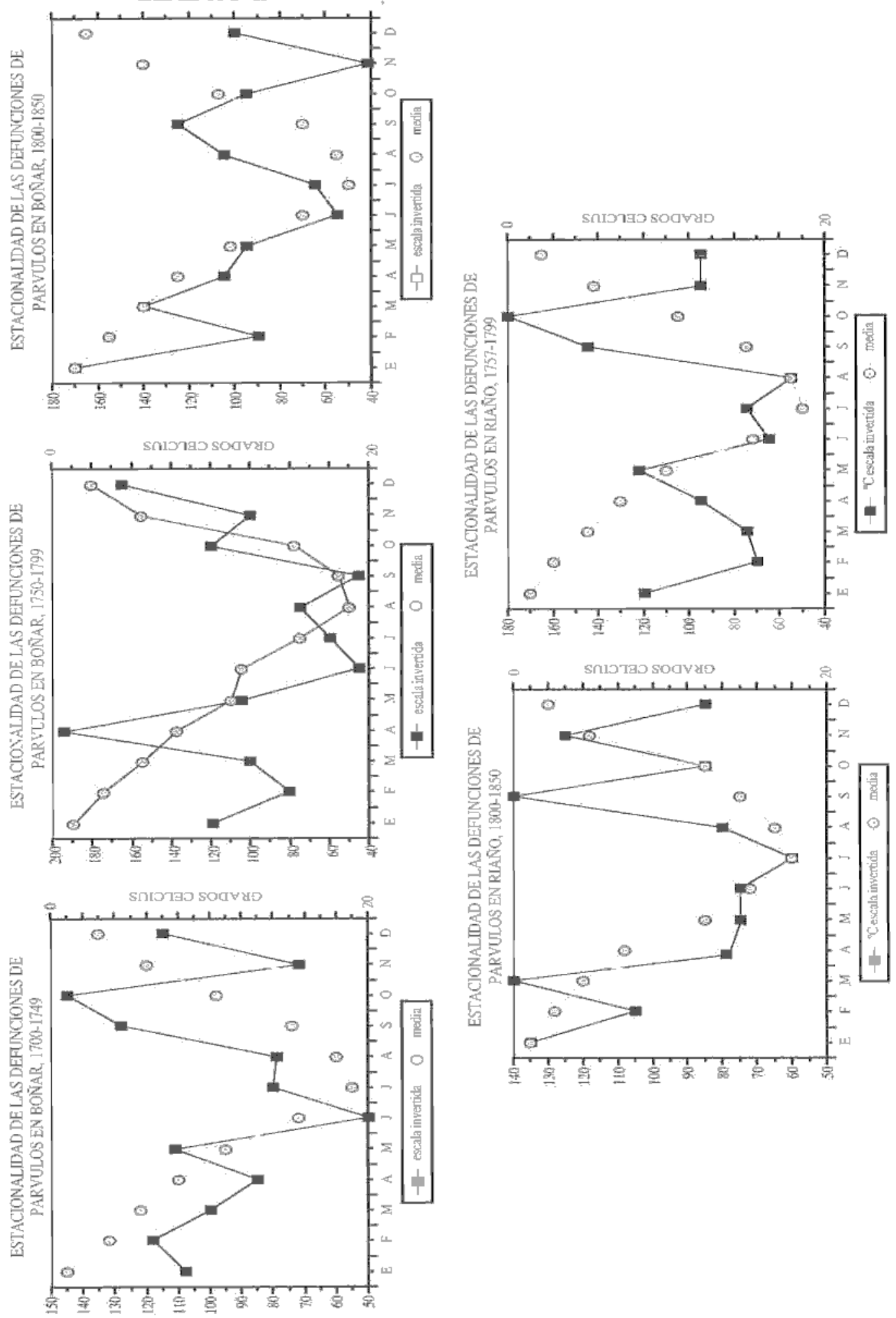

Estacionalidad de la mortalidad adulta e infantil

(siglos XVIII-primera milad del XIX)

\section{EN LA ESPAÑA INTERIOR}

Vicnle Perez Morede
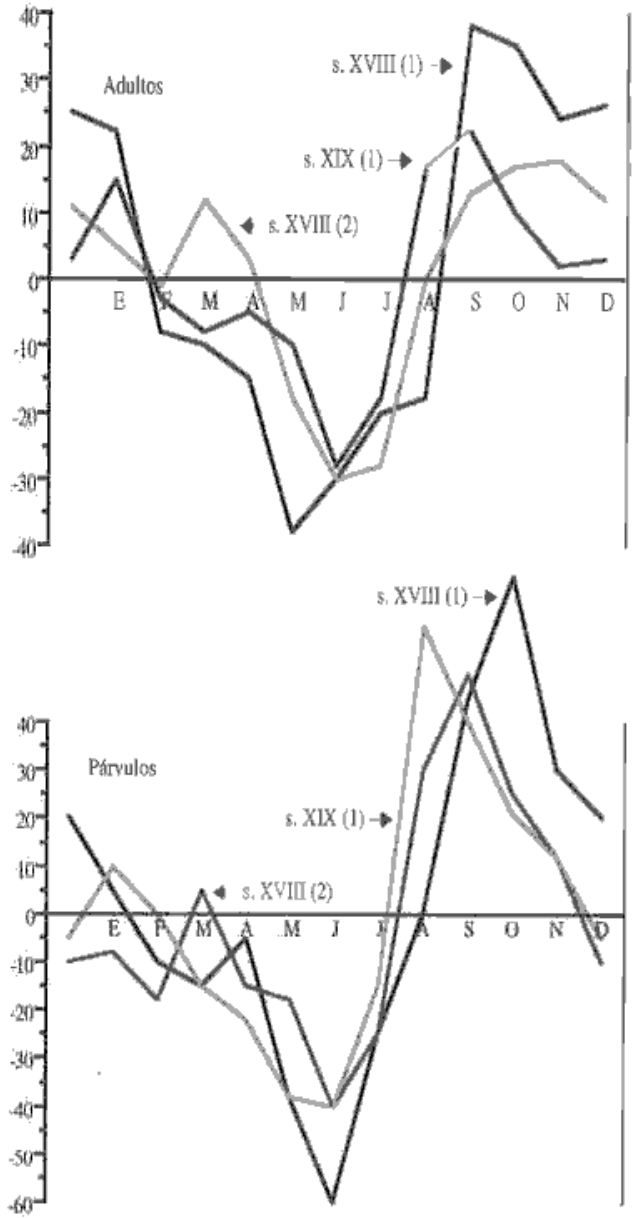

ESTACIONALIDAD MORTALIDAD ADULTOS

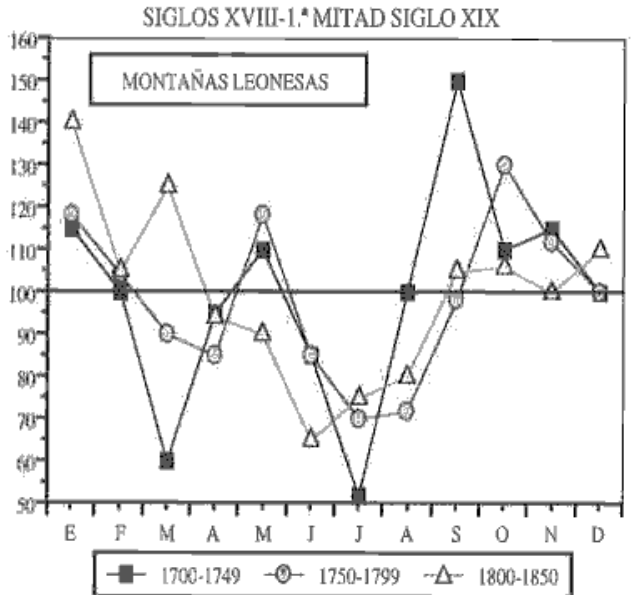

ESTACIONALIDADMORTALIDAD INFANTLL SIGLOS XVIII-1." MITAD SIGLO XIX

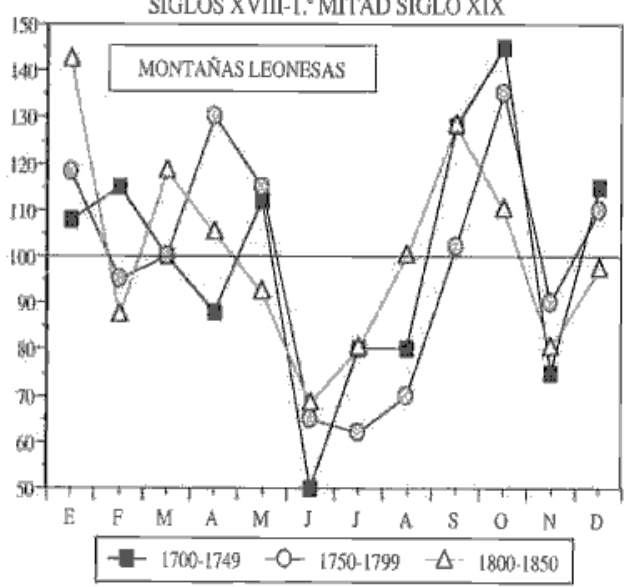

